\title{
DOUTORADO DA REDE AMAZÔNICA DE EDUCAÇÃO EM CIÊNCIAS E MATEMÁTICA SOB A PERSPECTIVA DOS EGRESSOS
}

\author{
AMAZON NETWORK DOCTORATE IN SCIENCES AND MATHEMATICS \\ EDUCATION FROM THE PERSPECTIVE OF THE GRADUATES
}

Ana Claudia Tasinaffo Alves ${ }^{1}$

ORCID iD: 0000-0003-0670-1978

Irene Cristina de Mello ${ }^{2}$

ORCID iD: $\underline{0000-0003-4042-7503}$

\begin{abstract}
RESUMO
A formação em nível stricto sensu no Brasil ocorreu, por muito tempo, nos grandes centros, sobretudo nas regiões Sul e Sudeste. A Rede Amazônica de Educação em Ciências e Matemática (REAMEC) tem contribuído para mudar tal cenário, formando doutores para a região da Amazônia Legal. A pesquisa realizada teve como objetivo analisar como a REAMEC proporcionou mudanças na carreira profissional do doutor egresso, e analisar as percepções dos egressos em relação à formação obtida no processo de doutoramento. A abordagem da pesquisa é de cunho qualitativo, descritivo e exploratório, tendo como instrumento de produção de dados entrevistas e levantamento na plataforma Lattes com informações dos currículos dos egressos da turma 2011. A análise das entrevistas foi elaborada mediante análise de conteúdo de Bardin. Com os dados obtidos nas entrevistas, três categorias emergiram: satisfação acadêmica, financiamento e oportunidade de permanência na Amazônia Legal. A REAMEC formou 130 doutores até dezembro de 2019, e os entrevistados deste estudo mostraram-se satisfeitos com a formação recebida e narraram como a rede foi importante em sua trajetória profissional e de igual importância foi a sua formação ter ocorrido na região na qual atuam. O estudo possibilitou mostrar que a REAMEC é um programa consolidado na região e que possibilita, a passos largos, a constituição de grupos de pesquisas e programas de pós-graduação na área.
\end{abstract}

Palavras-chave: REAMEC. Ensino de Ciências e Matemática. Doutorado em Rede.

\begin{abstract}
Formation at the Stricto Sensu level in Brazil has been taking place for a long time in the large centers, mostly in the South and Southeast regions. The Amazon Network for Sciences and Mathematics Education (REAMEC) has been contributing towards changing such situation by formation $\mathrm{PhD}$ for the Legal Amazon region. The present a study carried out about how the REAMEC has provided changes in the professional career of the graduated $\mathrm{PhD}$, as well as analyzing the graduates' perceptions regarding the formation received in the $\mathrm{PhD}$ process. The research approach is of a qualitative, descriptive and exploratory nature, using data production, interviews and ascertainment in the Lattes platform with information from the 2011 class graduates' curricula as its instrument. The analysis of the interviews was elaborated through Bardin's content analysis. From the data obtained in the interviews, three

\footnotetext{
${ }^{1}$ Doutora em Educação em Ciências e Matemática (REAMEC/UFMT). Professora do Instituto Federal de Educação, Ciência e Tecnologia de Mato Grosso (IFMT), Confresa, Mato Grosso, Brasil. Endereço para correspondência: Avenida Vilmar Fernandes, 300, Santa Luzia, Confresa, Mato Grosso, Brasil, CEP: 78652-000. E-mail: anatasinaffo@gmail.com.

${ }^{2}$ Doutora em Educação (USP/São Paulo). Professora do Departamento de Química da Universidade Federal de Mato Grosso (UFMT), Cuiabá, Mato Grosso, Brasil. Endereço para correspondência: Rua 46, 305, Boa Esperança, Cuiabá, Mato Grosso, Brasil, CEP: 78068-742. E-mail: ireneufmt@ gmail.com.
} 
categories emerged: academic satisfaction, financing, and the opportunity to remain in the Legal Amazon. REAMEC trained $130 \mathrm{PhD}$ by December 2019, and the interviewees in this study displayed satisfaction with the training received and stated the importance of the Network for their professional background, as well as how important it was to graduate in the region where they work. The study allowed to show how REAMEC is a consolidated program in the region that makes it possible through large steps to constitute research groups and post-graduation programs in the area.

Keywords/Palabras clave: REAMEC. Teaching of Sciences and Mathematics. Network Doctorate.

\section{INTRODUÇÃO}

A Amazônia Legal é um território brasileiro, instituído em 1953, e de acordo com o Instituto de Pesquisa Econômica Aplicada (IPEA) ocupa uma área de $5.215 .423 \mathrm{~km}^{2}$, é composto por nove estados: Acre, Amapá, Amazonas, Mato Grosso, Maranhão, Pará, Rondônia, Roraima e Tocantins. Essa área corresponde a 59\% do território brasileiro, e a estimativa de população para o ano de 2014 do Instituto Brasileiro de Geografia e Estatística (IBGE) era de 29.202.694 habitantes (BRASIL, 2020).

Além do crescimento populacional, no território da Amazônia Legal residem 56\% da população indígena brasileira. Os limites territoriais da Amazônia Legal ocorreram pela “necessidade de planejar o desenvolvimento econômico da região e, por isso, não se resumem ao ecossistema de selva úmida, que ocupa $49 \%$ do território nacional e se estende também pelo território de oito países vizinhos" (BRASIL, 2008, n. p.). É uma região que tem crescido em termos populacionais e, portanto, é "imprescindível que haja investimentos para uma educação de qualidade" (ALVES; MELLO, 2019, p. 3).

A Rede Amazônica de Educação em Ciências e Matemática (REAMEC) surgiu da necessidade em formar doutores para atuarem em cursos de formação de professores na Amazônia Legal. Após reuniões entre doutores de instituições, Universidade Federal de Mato Grosso (UFMT), Universidade Federal do Pará (UFPA) e Universidade do Estado do Amazonas (UEA) entre outras, foi elaborado um projeto de Pós-Graduação em Educação em Ciências e Matemática (PPGECEM) e submetido à Coordenação de Aperfeiçoamento de Pessoal de Nível Superior (Capes), assim, em 2010 houve a abertura do primeiro edital.

A primeira turma iniciou em 2011, com trinta ingressantes, e 29 deles concluíram o doutorado. Esses egressos do PPGECEM/REAMEC foram sujeitos de um estudo mais amplo que buscou entender quais as concepções deles em relação à formação recebida e como o título promoveu mudanças em suas atuações profissionais. Nessa perspectiva, esse estudo buscou 
investigar as mudanças promovidas pela REAMEC na carreira profissional dos egressos da primeira turma.

Na percepção de Huberman (2000, p. 38), “o desenvolvimento de uma carreira é, assim, um processo e não uma série de acontecimentos. Para alguns, este processo pode parecer linear, mas, para outros, há patamares, regressões, becos sem saída, momentos de arranque, descontinuidades". O professor passa por processos de mudanças em sua trajetória profissional, nem sempre positivas, e independentemente do nível de atuação sua trajetória poderá ter altos e baixos e isso faz parte do seu desenvolvimento profissional.

Definir etapas nas carreiras de docentes de diversas origens, formações trajetórias, e que vivem em contextos profissionais diferentes, seja em relação à estrutura disponível, políticas de carreiras, proventos, reconhecimento perante a sociedade, entre outros, é difícil.

Assim, o objetivo deste estudo foi conhecer de que forma a REAMEC trouxe mudanças na carreira profissional do doutor egresso e analisar as percepções dos egressos em relação à formação obtida no processo de doutoramento. O referencial teórico apresenta a Pós-Graduação em Rede no Brasil e um breve histórico da REAMEC. Na sequência, apresenta-se a metodologia de pesquisa e, em seguida, a análise dos resultados.

\section{PÓS-GRADUAÇÃO EM REDE NO BRASIL}

Um levantamento de cursos de pós-graduação na plataforma Sucupira, realizada em março de 2020, mostrou que havia nove programas de pós-graduação stricto sensu acadêmicos, com cursos de mestrado e/ou doutorado, sendo sete profissionais e dois acadêmicos funcionando em rede no país. No Brasil, as associações em rede são recentes, pois o mais comum é que cada programa de pós-graduação seja vinculado a uma IES. Foi a partir do V Plano Nacional da Pós-Graduação (2005-2010) que surgiu a orientação de criação de programas em rede, com o intuito de reduzir as distorções regionais em relação à oferta de programas stricto sensu.

As redes são formadas por mais de uma IES, sendo que a configuração da uma rede ocorre quando as responsabilidades e atribuições das instituições associadas são compartilhadas e a concepção de sua proposta apresente especificidades que levam a Capes, após verificar que estão garantidos todos os requisitos de qualidade, adequado funcionamento e estabilidade do curso, a admitir que o curso se enquadra na categoria especial de "Curso promovido por uma Associação de IES”, o que poderá permitir que seu núcleo de professores permanentes 
(responsáveis pelas suas atividades básicas de ensino, pesquisa e orientação) seja formado por docentes/pesquisadores das instituições por ela formalmente consideradas integrantes dessa associação. Assim, não basta que um grupo de IES se autodefina promotor de um curso; a Capes deverá avaliar e aprovar a qualidade e a viabilidade desse curso, e enquadrá-lo como promovido por uma “Associação de IES", e o CNE deverá reconhecer e homologar essa situação no parecer referente ao reconhecimento de tal curso (BRASIL, 2007, p. 2).

A Capes havia definido, em 2007, quatro tipos de associações possíveis entre as IES: Associação Ampla (AA), Associação em Rede (AR), Associação Temporária (AT) e Associação Parcial (AP) (BRASIL, 2007). No entanto, em 2014, uma nova orientação da Diretoria de Avaliação da Capes preconizava que não fossem mais utilizadas as tipologias predefinidas, mas que os programas detalhassem minuciosamente como seria a associação das IES e que fossem "explícitos o correspondente regimento e os comprometimentos formais que vão disciplinar e assegurar o funcionamento do curso" (BRASIL, 2014, p. 1).

Tal mudança ocorreu de forma a atender a diversidade de situações do contexto do Sistema Nacional da Pós-Graduação (SNPG). Mesmo com modificações, a seguir faz-se um breve relato dos tipos de associações possíveis que ocorrem entre IES.

A Associação Ampla, de acordo com a Capes (BRASIL, 2007, p. 3), era a associação de duas e até quatro IES para "institucionalmente articulada e oficializada, copatrocinar a criação e manutenção do programa de pós-graduação". A IES pode recorrer à Associação Ampla caso ainda não atenda aos requisitos mínimos para garantir, de forma independente, a criação de um curso ou uma situação em que a IES tenha mestrado, mas para ofertar doutorado ainda necessite da associação. Ou quando, mesmo tendo corpo docente e infraestrutura, julgue necessária a associação para atender a objetivos específicos da localidade ou região.

Associação em Rede é basicamente uma Associação Ampla, formada por cinco ou mais instituições, e, de acordo com a Capes, se constitui uma categoria à parte,

[...] devido à complexidade desse tipo de iniciativa, no que diz respeito à concepção, estruturação e forma de funcionamento do curso, à heterogeneidade das atribuições e responsabilidades das IES participantes, às exigências adicionais que deverão envolver o acompanhamento sistemático e a avaliação trienal desses programas e cursos [...] (BRASIL, 2007, p. 3).

A associação em Rede é o tipo de associação em que a REAMEC se enquadra, pois, até 2020, é formada por vinte e seis IES públicas federais, estaduais e privadas em prol da formação de professores de Ciências e de Matemática na região da Amazônia Legal. 
A Associação Temporária pode ser utilizada por IES que mantêm grupos de pesquisas produtivos e qualificados, no entanto, para manter um programa falta-lhes experiência em orientação. Por exemplo, a associação pode ser feita até que a IES tenha autonomia para seguir em frente com o programa que foi consolidado sem a necessidade de permanência da associação.

O tipo de Associação Parcial é quando apenas uma IES é mantenedora do programa, mas conta com relevante colaboração de outra IES em atividades de ensino, pesquisa e orientação. Essa associação também é institucionalmente oficializada e contínua para a manutenção do programa.

No documento mais recente, a Capes caracteriza distinções importantes, entre as quais cursos em forma associativa, cooperação regular entre IES e oferta e/ou atendimento de turmas especiais no campus de outra IES:

\begin{abstract}
Primeiro, não se caracteriza como Curso em forma associativa de IES aquele que tem sua atuação fortalecida por parceria, cooperação, intercâmbio nacional com outras IES, como é próprio de todo bom programa de pós-graduação ou grupo de pesquisa. Essa cooperação, quase sempre derivada de Convênio, Acordo, Edital específico ou temático é sistematicamente, e cada vez mais, mantida por todos os programas de pósgraduação (mesmo aqueles vinculados a uma só IES - correspondente ao modelo tradicional de pós-graduação). Tanto o APCN como o Coleta de Dados da CAPES têm campos próprios para a caracterização e o destaque desse importante tipo de iniciativa. [...] Segundo, a proposta de Curso em forma associativa corresponde a uma proposta de criação de curso novo, e não do que se convencionou chamar de Mestrado Interinstitucional, Minter, ou Doutorado Interinstitucional, Dinter, que se referem à oferta ou atendimento de uma turma de alunos sob condições especiais (isto é, diferentes daquelas previstas na proposta avaliada pela CAPES e que fundamentou o ato de reconhecimento do curso pelo CNE/MEC). [...] Terceiro, a possibilidade ou potencial participação de docentes no ensino ou na pesquisa não é característica e condição que, per se, enseja a justificativa de apresentação de proposta de curso em forma associativa. A participação de docentes (na condição de professores colaboradores ou visitantes) de outras instituições ou de outros programas em 1 (um) curso de uma dada IES é usual, uma vez atendidos os critérios próprios de cada instituição e os indicadores de participação relativa (definida pelo CTC-ES) em termos de docentes permanentes, colaboradores e visitantes (BRASIL, 2014, p. 1).
\end{abstract}

Independente da forma de associação, a criação das redes tem propiciado a oferta de programas para as regiões onde o número de doutores não atende aos requisitos para a implantação de cursos de mestrado e doutorado em apenas uma IES, e assim tem potencial para diminuir os desequilíbrios em relação às regiões, como o Sul e Sudeste.

Para fins de avaliação, a Capes considera a participação de todos os docentes como sendo de um único curso, independentemente do número de IES envolvidas na associação. E apesar das dificuldades de se manter uma Rede, ainda são necessárias essas associações para 
poder ampliar a oferta de cursos de mestrado e doutorado em regiões onde ainda há uma baixa taxa de cursos e vagas.

Algumas redes destacam-se, em especial nas regiões Norte e Centro-Oeste, ou mesmo Redes da Amazônia Legal, como é o caso da REAMEC que, por meio de uma Associação em Rede, tem 28 IES dos nove estados da região como conveniadas no curso de doutorado do Programa de Pós-graduação em Educação em Ciências e Matemática; e a Rede de Biodiversidade e Biotecnologia da Amazônia Legal (BIONORTE), com formação de doutores para o conhecimento da biodiversidade e desenvolvimento da Biotecnologia da região. A seguir apresenta-se um breve histórico da formação da REAMEC e como tem funcionado.

\title{
3 A REDE AMAZÔNICA DE EDUCAÇÃo EM CIÊNCIAS E MATEMÁtiCA (REAMEC)
}

A elaboração do projeto de curso de doutorado acadêmico da REAMEC foi no ano de 2008, e uma das metas, no longo prazo, da área e de áreas afins, por meio de ação acadêmica colaborativa entre as IES e os doutores existentes na região, é a de formar 150 doutores até 2020 para atender a formação de professores em todo território amazônico (REAMEC, 2008).

Darsie (2011, p. 361), que fez parte da comissão de elaboração do projeto da REAMEC, relata que,

\begin{abstract}
a comissão de elaboração do Projeto entende ser a proposta de doutorado uma forte possibilidade de formar doutores formadores de pesquisadores e professores da área que, por meio das pesquisas e atuação na formação inicial e continuada e na educação informal, poderão diagnosticar a realidade da Região, contribuindo para a construção de conhecimentos na área e preparando profissionais qualificados para nela melhor intervir com vistas ao desenvolvimento regional sustentável e para promoção de justiça social.
\end{abstract}

O projeto do doutorado possui duas linhas de pesquisa, sendo a linha 1: Formação de Professores para a Educação em Ciências e Matemática; e linha 2: Fundamentos e Metodologias para a Educação em Ciências e Matemática. A escolha das linhas é realizada no momento de inscrição nos editais de seleção, quando o candidato envia um projeto de pesquisa de acordo com a linha escolhida.

Em 2010, o projeto foi aprovado pela Capes, e no mesmo ano foi publicado edital para a seleção da primeira turma que iniciaria no ano seguinte. Desde então o programa seleciona mestres para a formação em nível doutoral a cada biênio. No Quadro 1 consta o número de 
instituições conveniadas, de vagas ofertadas, de inscritos, de doutores credenciados e colaboradores de cada um dos cinco editais já finalizados.

\begin{tabular}{|l|c|c|c|c|c|}
\hline \multicolumn{1}{|c|}{ Turmas/Editais } & $\mathbf{2 0 1 1}$ & $\mathbf{2 0 1 3}$ & $\mathbf{2 0 1 5}$ & $\mathbf{2 0 1 7}$ & $\mathbf{2 0 1 9}$ \\
\hline IES & 23 & 25 & 25 & 26 & 28 \\
\hline Vagas ofertadas & 30 & 44 & 60 & 30 & 60 \\
\hline Inscritos & 86 & 102 & 101 & 87 & 112 \\
\hline Doutores Credenciados & 28 & 32 & 30 & 39 & 42 \\
\hline Doutores Colaboradores & 03 & 06 & 13 & 13 & 20 \\
\hline
\end{tabular}

Quadro 1 - A REAMEC em números

Fonte: Dados organizados pelas autoras com base nos editais de seleção da REAMEC (2019).

O quantitativo de IES participantes do convênio da REAMEC sofreu um pequeno aumento ao longo do período de existência da Rede. Cada instituição conveniada tem termo de convênio assinado pelos seus reitores. Cada IES assume o papel de colaborar para que seus docentes possam participar do curso de doutorado. No entanto, as IES conveniadas proporcionam a formação, mas de uma IES para outra há diferença de apoio.

Algumas das IES apenas liberam os seus professores nos períodos de aula, que são condensados, enquanto algumas apoiam com bolsas ou passagens e diárias para esses períodos de aula. As aulas das disciplinas obrigatórias ocorrem nos três polos, de forma condensada, geralmente entre o final de janeiro e início de março e no mês de julho do primeiro ano de formação. As disciplinas eletivas ocorrem tanto nos polos quanto nas IES credenciadas, dependendo da organização dos docentes do curso e dos doutorandos.

A variação no número de vagas ocorre, geralmente, conforme a disponibilidade dos docentes orientadores, e até 2019 foram ofertadas 224 vagas para um total de 488 inscritos. Pelos dados dos editais percebe-se que houve um aumento no total de docentes credenciados e colaboradores, isso contribui para que a Rede ofereça mais vagas, como fica evidenciado no edital de seleção para a turma 2019, no qual foram ofertadas 60 vagas. Este último edital foi o que teve maior número de inscritos.

As aulas ocorrem em três polos diferentes, nos quais os ingressos são distribuídos. Os polos da REAMEC são: Polo Acadêmico de Cuiabá, localizado na Universidade Federal de Mato Grosso (UFMT), local em que também se encontra a coordenação geral do programa; Polo Acadêmico de Belém, que se localiza na Universidade Federal do Pará (UFPA); e Polo Acadêmico de Manaus, localizado na Universidade do Estado do Amazonas (UEA). 
Da primeira turma, dos 30 ingressantes, 29 defenderam suas teses, e apenas um não conseguiu concluí-la por problemas de saúde. Ao final de 2019, 130 professores das diversas IES conveniadas defenderam suas teses e concluíram o curso de doutorado. Na Figura 1 consta o total de docentes egressos da REAMEC distribuídos por estados federativos de acordo com informações contidas nos currículos disponíveis na plataforma Lattes.

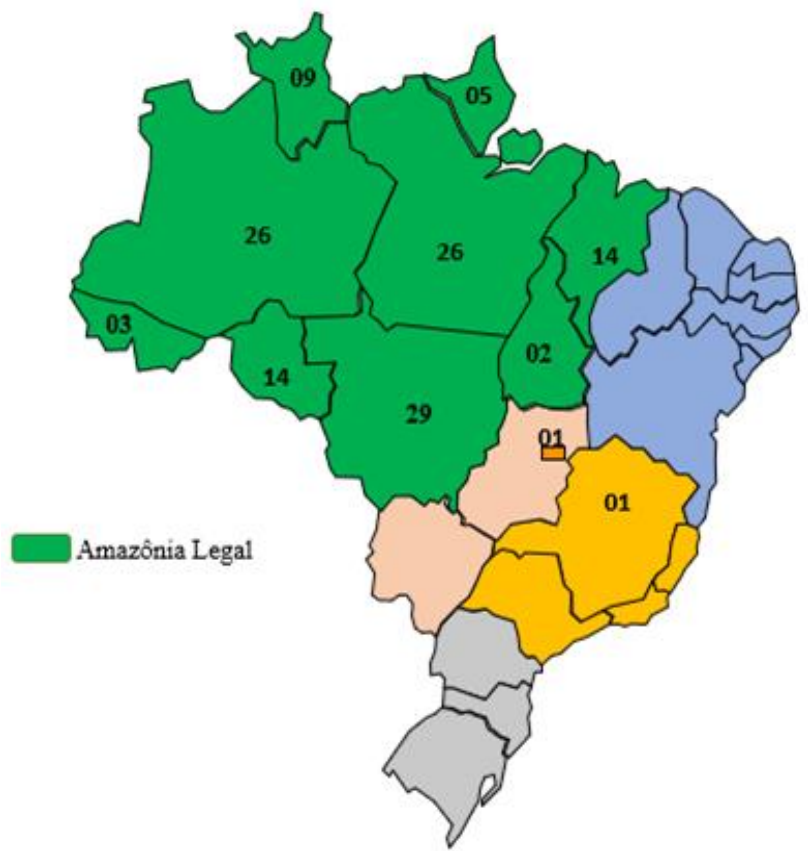

Figura 1 - Localização dos egressos por unidade federativa. Fonte: Dados organizados pelas autoras (2019).

Dos 107 doutores que concluíram o curso, apenas dois saíram da região da Amazônia Legal: um doutor, que saiu do estado do Amazonas para Minas Gerais por redistribuição, e uma doutora que foi removida, por cooperação técnica, para acompanhamento de cônjuge, do estado do Amapá para Brasília por período indeterminado. Constatou-se, portanto, que a REAMEC forma doutores e consegue fixá-los na região, e isso proporciona formação doutoral para professores formadores de professores e ainda possibilita a criação de novos mestrados na área de Ensino de Ciências e Matemática.

Na avaliação do quadriênio 2013-2016, o PPGECEM foi avaliado com nota 5, sendo avaliados quatro critérios pela comissão de avaliação da área de ensino. Os quatro critérios em que a REAMEC foi avaliada, com ficha diferente dos demais programas por ser um programa em rede, foram: Avaliação da Rede e de suas associadas; Discentes e Egressos; Corpo Docente; e Inserção Social. 
Para cada critério os conceitos obtidos podem ser: Muito Bom, Bom, Regular, Fraco e Insuficiente. Os conceitos obtidos em todos os critérios avaliados foram 'Muito Bom', e assim o PPGECEM passou de nota 4 para nota 5. A comissão afirmou ainda, em documento, que o programa da REAMEC já possui índices para alcançar a nota 6 , mas isso não foi possível, uma vez que a comissão de avaliação estabeleceu que não iria modificar as notas dos programas em 2 pontos nem para cima, nem para baixo, justificando que por ser uma área nova, com muitos programas e ainda em expansão, a "trava adicional" assegura uma avaliação mais prudente (BRASIL, 2017a, p. 21).

Um critério muito evidenciado na avaliação foi a Inserção Social, em que a comissão indicou ter um grande impacto para a região. Sobre esse critério, na Ficha de Avaliação da REAMEC consta:

\footnotetext{
Em relação à inserção social, o Programa tem um impacto grande, seja pela demanda a que atende, seja pela contribuição na formação de profissionais das IES da região. Percebe-se que o impacto educacional se dará por meio da melhoria do Ensino Superior, o que poderá em breve impactar a educação básica, por meio de uma formação qualitativamente melhor para os docentes da Educação Básica. Nesse contexto, a comissão sugere a mudança da nota do programa de 4 para 5 (BRASIL, 2017, p. 5).
}

A REAMEC proporcionou a formação de mais de 130 doutores para a região, e esse número vem crescendo a cada ano, com novos doutores sendo formados. A avaliação da Capes aponta que é um programa consolidado e que contribui para a formação de professores doutores da região, e um dos objetivos da Rede é que esses doutores formados consigam propor programas de mestrado na área de Ensino de Ciências e Matemática em seus respectivos Estados.

\section{METODOLOGIA}

A pesquisa foi realizada a partir de uma abordagem qualitativa do tipo estudo de caso, descritivo e exploratório, e, conforme Yin (2015), é utilizada quando se deseja entender um fenômeno real e contemporâneo. Gil (2009) argumenta que os estudos de caso enfatizam o contexto no qual ocorrem os fenômenos. Para a realização deste estudo selecionamos como sujeitos da pesquisa os egressos da primeira turma do PPGECEM/REAMEC.

Para a produção de dados optamos por entrevistar onze egressos, após ter realizado consulta aos currículos da Plataforma Lattes dos vinte e nove egressos da primeira turma (2011- 
2014). Os dados obtidos na consulta aos currículos foram publicados em 2017 (ALVES, MELLO, 2017). Para a realização da entrevista foram selecionados egressos de, pelo menos, um estado da Amazônia Legal e que se dispuseram a participar da pesquisa.

As entrevistas semiestruturadas foram agendadas e realizadas de acordo com a disponibilidade de cada entrevistado, assim, cinco entrevistas foram presenciais, nos locais de trabalho dos participantes, e o restante foi realizado on-line, no segundo semestre de 2017. Como as distâncias entre os municípios da pesquisadora e dos pesquisados são longas, as entrevistas foram realizadas utilizando-se as tecnologias de chamadas de vídeo pelo aplicativo WhatsApp ou por Skype. Para uma boa entrevista considera-se importante que o entrevistado sinta-se à vontade e possa discorrer livremente sobre sua trajetória profissional e a percepção sobre a formação recebida.

Todas as entrevistas foram realizadas por nós, mantendo regularidade na forma de conduzi-las. As transcrições foram realizadas sem auxílio de softwares ou de terceiros. Assim fez-se a textualização necessária para dar fluidez ao texto, retirando vícios de linguagem, com o cuidado de não modificar o conteúdo da fala do sujeito. Os excertos extraídos das entrevistas são apresentados em itálico e com fonte menor, na seção reservada aos resultados.

Os onze entrevistados são oriundos de oito estados que fazem parte da Amazônia Legal: Mato Grosso (3); Amazonas (2); Pará (1); Rondônia (1); Tocantins (1); Roraima (1); Amapá (1) e Acre (1), mas não foi possível entrevistar a egressa do Maranhão. Para proteger a identidade dos sujeitos entrevistados, todos receberam nomes de importantes cientistas para representá-los, com a manutenção do gênero. Os entrevistados foram assim nomeados: Descartes, Marie Curie e Marx (MT); Maria Mayer e Galileu (AM); Jane Goodall (PA); Lise Meitner (RO); Darwin (TO); Euclides (RR); Rachel Carson (AP); e Emmy Noether (AC).

A pesquisa foi cadastrada na Plataforma Brasil e autorizada pelo Comitê de Ética em Pesquisa, e todos os entrevistados assinaram o Termo de Consentimento Livre e Esclarecido.

Para analisar os dados produzidos optou-se pela análise de conteúdo (BARDIN, 2011), caracterizada como um conjunto de instrumentos metodológicos de análise das comunicações que utiliza procedimentos sistemáticos e objetivos de descrição do conteúdo das mensagens. A escolha da análise de conteúdo pautou-se no fato de que "a análise de conteúdo oscila entre os dois polos do rigor da objetividade e da fecundidade da subjetividade" (BARDIN, 2011, p. 15), e a subjetividade se faz presente na pesquisa que foi realizada, sobretudo nas entrevistas.

A análise de conteúdo é a análise das mensagens, comunicação em que uma das técnicas 
é a análise categórica temática e seu objetivo "é a manipulação de mensagens (conteúdo e expressão desse conteúdo) para evidenciar os indicadores que permitam inferir sobre uma outra realidade que não a da mensagem” (BARDIN, 2011, p. 52).

Para Bardin (2011, p. 148), "classificar elementos em categorias impõe a investigação do que cada um deles tem em comum com outros. O que vai permitir o seu agrupamento é a parte comum existente entre eles". Sendo assim, as categorias de análise não foram previamente nomeadas, elas emergiram durante as primeiras análises. Para Bardin (2011, p. 149), a categorização pode ser fornecida antes da análise ou ao final da operação, e as categorias podem resultar da "classificação analógica e progressiva dos elementos", ou seja, o "título conceitual de cada categoria só é definido no final da operação". As categorias de análise emergentes são apresentadas nos resultados.

\section{ANÁLISES E RESULTADOS}

No intuito de conhecer as percepções dos egressos sobre a formação doutoral recebida, nas entrevistas questionou-se: “1. Quanto a sua formação doutoral no PPGECEM/REAMEC, quais os desafios encontrados e como você avalia essa formação? 2. O que poderia mudar? 3. Você pode citar pontos positivos por ter feito o doutoramento na REAMEC? 4. Você pode citar pontos negativos por ter feito o doutoramento na REAMEC?"

Diante das respostas obtidas, três categorias emergiram: satisfação acadêmica; financiamento; e oportunidade de permanência na Amazônia Legal.

Para a categoria satisfação acadêmica os egressos afirmam estar satisfeitos e realizados com a formação recebida. Uma das entrevistadas, Maria Mayer, relata que o título de doutora mudou sua vida profissional, educacional e pessoal, e lhe propiciou muito mais trabalho e, principalmente, o envolvimento na pós-graduação, oportunidades de trabalhos com outros orientadores de outros programas e outras regiões, inclusive. E a entrevistada ainda contou que

[...] o doutorado me sustenta teoricamente para encaminhar uma pesquisa, o que não acontecia antes do doutorado, ele abre possibilidades também por eu estar numa instituição federal, por eu ter dedicação exclusiva [...] ele abre muitas possibilidades acadêmicas, quem é professor do ensino superior e quer realizar pesquisa é fundamental o doutorado, para propor um projeto, e ter uma sustentação teórica, conceitual daquilo que você quer trabalhar [...] você se sente mais confiante naquilo que você está fazendo, embora descubra que tem tanta coisa pra aprender (MAYER, 2017).

$\mathrm{Na}$ entrevista, Maria Mayer revelou o quanto está satisfeita profissionalmente, e o doutorado pelo PPGECEM/REAMEC lhe proporcionou oportunidades de crescimento e 
engajamento na pesquisa e na pós-graduação stricto sensu. Não obstante, citou dois desafios importantes: as questões financeiras para facilitar as mobilidades dos doutorandos; e a dificuldade de manutenção e criação de redes entre pesquisadores egressos da REAMEC.

Por sua vez, Galileu disse estar satisfeito com a formação recebida, com as oportunidades que surgiram após a obtenção do título de doutor, e, inclusive, ele atribui a sua identidade docente à formação doutoral, afirmando que

[...] foram os alunos que perceberam e fizeram eu perceber que eu estava passando por uma mudança, até na construção das avaliações, eles diziam - professor o senhor está diferente - os estudos e leituras na área de ensino já vinham fazendo uma transformação, porque você começa a ver com outros olhos [...] então comecei a perceber que não poderia seguir uma linha reta, porque o ensino não é reto, você precisa de diálogo, de abertura, verificar se o aluno está aprendendo, tudo isso comecei a perceber e fui sofrendo essa transformação gradativamente (GALILEU, 2017).

Do mesmo modo que Galileu e seus alunos observaram mudanças na prática do professor, Cunha (2013, p. 611) diz que "a formação de professores se faz em um continuum, desde a educação familiar e cultural do professor até a sua trajetória formal e acadêmica, mantendo-se como processo vital enquanto acontece seu ciclo profissional”. Desse modo, o professor está sempre aprendendo e estabelecendo sua carreira docente, e todo o seu contexto de vida familiar, acadêmica e profissional corrobora para a sua formação como um todo.

Emmy, outra entrevistada, possui quase 30 anos de carreira docente e ainda mostra entusiasmo pela profissão e sobre as mudanças percebidas com a obtenção do título de doutora. Para ela, ser doutora

muda tudo, desde reconhecimento dos colegas de trabalho, dos estudantes do curso de Licenciatura. Mas
penso que o principal são as oportunidades de projetos financiados pela Capes, pela Fundação de
Ampara à Pesquisa do Acre (FAPAC), que podemos incluir alunos de mestrado, alunos da graduação.
Recebi um convite para fazer uma palestra de abertura na Semana de Ciência e Tecnologia aqui do
estado, eles estavam em busca de um trabalho que tivesse inovação, e ficaram sabendo da minha pesquisa
desenvolvida no doutorado e me convidaram, portanto muda muitas coisas (NOETHER, 2017).

Outra entrevistada, Rachel Carson, que está em período de cooperação técnica em outra instituição de ensino, fora da Amazônia Legal, afirmou estar uns 80\% satisfeita. Isto porque ainda está se adaptando na nova IES, e também com o clima e com a cidade, mas ama o seu trabalho e sobre a sua formação doutoral declara:

[...] em relação ao doutorado, tenho plena satisfação do que consegui, só não diria totalmente por que gostaria de ter publicado mais. Mesmo durante o período das disciplinas consegui produzir três artigos que só agora foram submetidos às revistas científicas [...] (CARSON, 2017).

Era objetivo de Carson, segundo seu relato, cursar um doutorado que lhe permitisse identificar-se como profissional da educação, o que, na formação inicial, ele não era, mas que 
a formação doutoral lhe propiciou essa segurança, complementando o seu fazer docente. Freitas (2002, p. 224) considera que a carreira docente na Educação Superior é muito mais do que dar aulas; é necessário ter clareza da diferença entre ter um emprego ou desenvolver a carreira de professor. Para essa autora, o trabalho acadêmico inclui, necessariamente, "a pesquisa, a investigação, a ousadia e o risco de não apenas repetir as ideias dos outros, mas também desenvolver suas próprias e posteriormente ajudar na construção das de seus alunos”.

Descartes, outro egresso entrevistado, se diz satisfeito com a formação doutoral recebida, pois

quanto mais distante nós ficamos da formação, maior o nosso grau de satisfação, porque vemos as oportunidades que vão se abrindo, mais do que quando nós estamos mais próximos. E durante o doutorado vemos muito mais as responsabilidades, e as dificuldades de terminar (DESCARTES, 2017).

Para Darwin, o título de doutor muda a vida profissional e acadêmica, ele diz ter mudado muitas coisas, dentre as quais

[...] a progressão salarial, que é uma questão financeira, e uma série de outras questões dentro da universidade. Ao terminar o doutorado, começou a vir as outras demandas da universidade, assumi coordenação do curso de Pedagogia. Logo na sequência eu criei um grupo de pesquisa. E, claro, as oportunidades que vem em decorrência de ser doutor, participar do programa de pós-graduação, ser convidado para as bancas, aberturas para publicação aumentam bastante, a procura pelos alunos etc. Com o título você muda o lugar de fala, a gente ganha um status de debate que é importante a partir desse processo. A gente passa a estudar dentro de um determinado campo de ensino, buscamos construir uma carreira, para que possamos ser referenciados, e mais que isso ser reconhecido dentro desse campo (DARWIN, 2017).

Poucos entrevistados assumem que a questão financeira é um fator que muda após a formação, considerando-se que a carreira profissional do docente das IES públicas está relacionada à titulação acadêmica. Mas, semelhante aos demais, Darwin citou também as oportunidades que vêm junto com as responsabilidades.

Curie afirma que o título de doutora lhe trouxe

[...] segurança, autoestima, clareza epistemológica, o que resultou por exemplo em maior facilidade na seleção de textos didáticos para uso didático, melhorou a seleção de conteúdo, a organização e o planejamento das aulas, a condução da formação de professores. A segurança é inclusive no sentido de me sentir mais livre, mais liberdade para me posicionar, para dialogar com os textos que não são da minha linha e, portanto, são obrigatórios para a leitura com os textos que são da minha linha, como é que faz isso dentro da mesma disciplina da mesma sala (CURIE, 2017).

Ela destacou o quanto a formação doutoral contribuiu para a sua atuação profissional, o que corrobora a avaliação da Capes, que avaliou a Inserção Social do programa com conceito 'Muito Bom' (BRASIL, 2017).

Euclides afirmou que as mudanças após a obtenção do título são culturais, presentes no local onde atua, e declarou: 
"quando você adquire um título de doutor, os outros doutores, meio que te dizem assim: seja bem-vindo ao clube" (EUCLIDES, 2017).

Ele também constatou que apareceram mais oportunidades após o doutorado, pôde concorrer a cargos dentro da universidade, recebeu convites para participar de eventos, contribuir com banca e que,

“em termos de reconhecimento, foi bastante proveitoso" (EUCLIDES, 2017).

Marx, outro egresso, disse que houve melhoria após a formação recebida no sentido de compreender melhor a sua profissão e a problemática de formar professores. Mas, para Marx, politicamente, a situação do país gera interferências negativas na satisfação profissional, pois

“nós estamos vivendo uma época que está difícil, somos podados de tudo quanto é lado. Essas crises políticas que nós temos aí, são muito ruins para a formação, para a educação, difícil se falar se teve melhoria” (MARX, 2017).

E reforça que a melhoria obtida foi intelectual, de compreensão da formação docente. Para Cavalcanti e Martines (2018, p. 37), “a formação docente é complexa, no sentido de que não envolve apenas um ou outro aprendizado técnico ou saber específico, mas se dá numa teia de saberes e práticas que se entrecruzam num processo social e pessoal dinâmico".

Outra categoria que emergiu nas respostas dos entrevistados foi o financiamento, o qual ocorria de forma diferente para os doutorandos durante o curso, de acordo com a instituição em que eram professores.

Galileu apontou que a falta de recursos impede que a rede funcione em plenitude, como ocorreria se professores de outras regiões e polos ministrassem disciplinas tanto obrigatórias quanto eletivas. E também o fato de que os recursos para as bancas de qualificação e defesa são buscados pelos doutorandos, que recorrem às suas instituições de origem para o financiamento das passagens.

Rachel cita a questão do financiamento por parte das IES conveniadas, em que há diferenças no tratamento dos doutorandos em cada instituição,

[...] acho que o principal deles é a falta de recursos, acompanhamos isso bem de perto, vários colegas que tiveram que atrasar suas pesquisas, tendo casos em que não conseguiram concluir o módulo porque não tinha apoio da sua instituição. Embora o programa tivesse instituído documentos de apoio, por exemplo, a universidade em que trabalho assinou o termo de convênio, então eu não me afastei integralmente das atividades para o doutoramento, tinha redução de carga horária, dessa forma eles conseguiam subsidiar com passagens e as diárias para eu participar dos módulos do doutorado, (CARSON, 2017).

Descartes disse que o único ponto negativo foi o financiamento por parte das IES conveniadas, entendido de modo diferente por elas, gerando para alguns doutorandos problemas em relação ao apoio para as passagens para cursar as disciplinas. Afirma que a sua instituição 
colaborou, mas não havia instituído mecanismos para esse apoio, então não se sabia quem pagava as passagens, se a reitoria ou o campus. E por ser a primeira turma, isso ficou bem difícil.

As principais citações sobre a ausência do financiamento relacionaram-se à participação das várias etapas do curso, a dificuldades para obter recursos para participar das disciplinas obrigatórias e optativas, dos Seminários de Pesquisa I e II, que sempre ocorriam em Belém e Manaus, respectivamente, além de eventos nacionais e internacionais. Segundo o relato de Rachel, Descartes, Curie, Lise, Jane, Marx e Euclides, muitos colegas não conseguiram receber diárias, passagens ou qualquer apoio de suas instituições. Os egressos que receberam algum tipo de apoio financeiro de suas IES também destacaram que os colegas passavam dificuldades, alguns interromperam disciplinas por falta de recursos financeiros.

Foi identificado nas entrevistas que as IES conveniadas financiam seus doutorandos de forma diferenciada, uns ajudam com bolsas, passagens e diárias, afastamentos de um ou dois anos enquanto outras IES se negam a oferecer qualquer tipo de auxílio.

A categoria oportunidade de permanência na Amazônia Legal mostra, conforme destacam as falas dos egressos, a importância de cursar o doutorado na região da Amazônia Legal.

A egressa Rachel Carson (2017) afirmou que, antes de 2010 (ano do primeiro edital da REAMEC), precisaria estudar em outro estado fora da região,

\footnotetext{
"se eu tivesse feito um doutorado em educação na época, teria que ter saido para fazer um doutorado fora do contexto Amazônia, e teria que estudar com pessoas que não entendiam a nossa realidade da Amazônia".
}

No caso de Descartes, ao se deparar com o edital da REAMEC, em 2010, a primeira coisa que lhe chamou a atenção foi a linha de pesquisa. Era, segundo ele, exatamente o que desejava fazer, além de ser na região em que ele estava começando a trabalhar, e poder unir o útil ao agradável. Disse ainda que o fato de ser um doutorado contributivo para a atuação profissional e estar próximo eram fatores relevantes, pois estando recentemente atuando na IES, sair seria um fator complicador, e poder fazer o doutorado sem precisar fazer mudança de domicílio foi um fator determinante para a escolha do programa.

Outra egressa, Lise, contou que precisou esperar durante 12 anos a oportunidade para fazer doutorado. Ela participou de dois processos seletivos para fazer doutorado, um em Minas Gerais e outro no Amazonas, e apesar de ter sido aprovada, a distância e a dificuldade em sair 
e deixar a família fizeram com que desistisse de cursar doutorado, até que o edital da REAMEC surgiu e ela viu a oportunidade de obter a titulação sem precisar mudar de cidade ou de Estado.

Para Curie, a escolha da REAMEC ocorreu por alguns motivos. Seu desejo era trabalhar com objetos e problemáticas da região amazônica e do estado de Mato Grosso. Ela tinha interesse, desde a graduação, pelas questões de tecnologia e sociedade e depois também trabalhou com as questões de educação ambiental, e o fato de ter trabalhado em uma escola agrotécnica, com estudos de química do solo e química da nutrição das plantas fez com que se aproximasse das questões ambientais (CURIE, 2017).

Marie Curie ainda considerou o fato de que fazer a formação doutoral em serviço era importante porque ela havia acabado de transitar de uma escola para outra e de um campus para o outro. E era importante fazer a pós-graduação sem o afastamento das atividades, portanto, disse, foi

[...] uma somatória de fatores, que vai desde a questão da temática com a qual eu trabalharia, a formação em serviço, o trabalho interinstitucional, de uma formação numa instituição que eu já conheço também, e tem mais o elemento da sustentação da família mesmo né, que eu sou mãe de três filhos, e tenho uma família, na época eu tinha uma maninha que eu entendia que eu poderia dar uma contribuição na vida dela e não gostaria de me mudar de Cuiabá para fazer um doutorado (CURIE, 2017).

A questão de não precisar mudar de domicílio para cursar o doutorado foi citada também por Marie Curie. A REAMEC propicia a titulação aos professores da região da Amazônia Legal e, mais importante, a formação para o doutorando que não consegue afastamento integral das atividades institucionais. Day (2001, p. 15) ressalta que o desenvolvimento profissional dos professores depende "das suas vidas pessoais e profissionais e das políticas e contextos escolares nos quais realizam sua atividade docente". A carreira docente está sempre em movimento, no sentido de aperfeiçoamento e busca de novos conhecimentos, assim ela sofre influências dos espaços e contextos de atuação desse profissional da educação.

Outro egresso, nomeado de Marx, disse que o principal fator para a escolha da REAMEC para cursar o doutorado foi a localidade:

É muito difícil sair, e por ser uma proposta diferente, foi legal, eu conheci Belém que eu não conhecia, conheci Manaus, além de ter essa relação, também política fazer uma a rede de pesquisadores em Educação na Amazônia Legal, onde a gente tem muita dificuldade nessa discussão, parece que é tudo igual ao Sul e não é, tem suas peculiaridades, isso também instigou a fazer o programa da REAMEC (MARX, 2017).

Para Marx, o ponto positivo de ter cursado o doutorado na REAMEC foi conhecer a região Norte e poder discutir os problemas educacionais dessa região sem precisar mudar de 
domicílio.

Jane Goodall, nome escolhido para outra egressa, relatou que a escolha do programa de doutorado da REAMEC foi, principalmente, por ser o único que lhe possibilitava não ter que se mudar da sua localidade. Ela fez toda a formação inicial do mesmo modo, e entende que assim garantiu a sua permanência no curso. Além disso, ela disse que pôde fazer sua pesquisa também sem se ausentar de sua cidade:

Outro ponto positivo é porque eu realizei a minha pesquisa de doutorado na minha localidade, então eu pude fazer uma pesquisa ação, envolvendo meus acadêmicos, e os professores da Educação Básica da minha cidade. Foi muito interessante, porque para eu fazer uma pesquisa que não fosse no local, não seria uma pesquisa que eu fizesse com tanto afinco, com total presteza e vontade de fazer. Foi no sentido de retornar, de contribuir para a comunidade aquilo que a gente recebe, o ensino superior gratuito, em forma de pesquisa, projetos de extensão, e assim poder retribuir. Considero muito interessante poder fazer o doutorado morando naquela localidade (GOODALL, 2017).

A importância em poder fazer o doutorado sem precisar se afastar de sua família e de sua residência apareceu na fala de Jane algumas vezes, e mostra a relevância da Rede para essa região. Antes da REAMEC, professores que sentissem o desejo e a necessidade da titulação em Educação em Ciências e Matemática tinham que se mudar durante quatro anos para cursar doutorados em outras regiões do país. Assim, muitos mestres eram impedidos de alcançar o título de doutor.

Diante das respostas dos egressos fica claro o papel essencial da REAMEC na Amazônia Legal, ao lhes propiciar a formação em nível doutoral sem sair da região e poderem discutir os problemas educacionais na área de ciências e matemática da região. Portanto, fazer um doutorado na região é um facilitador para esses mestres.

Retomando o que escreveu Darsie (2011), o programa de doutorado da REAMEC tinha a possibilidade de formar doutores pesquisadores para a realidade da Amazônia Legal, e pelo estudo realizado e apresentado até aqui se constata que os doutores egressos dessa Rede estão intervindo em suas IES, contribuindo com pesquisas e formando professores para a Educação Básica, e colaborando para o fortalecimento da área de Ensino de Ciências e Matemática na referida região.

A REAMEC se mostra fundamental para a formação de doutores na Amazônia Legal, uma região que tem uma distorção muito grande no número de vagas em relação às outras regiões do país, sobretudo Sul e Sudeste. E contribui para a formação de doutores, os quais permanecem nessa região. Assim, cada pesquisa de tese de doutoramento tenta entender os problemas locais e seus contextos, resolver problemas que em outros programas, em outros estados, talvez não fosse possível. 


\section{CONSIDERAÇÕES}

Pelo olhar dos doutores egressos da primeira turma formada pela REAMEC fica claro que a Rede propicia a formação sem que os professores saiam da região, mostrando que a maioria dos egressos permanece atuando na Amazônia Legal. Na percepção dos egressos, fica evidenciada a satisfação pela formação acadêmica recebida, o envolvimento com a pesquisa e as possibilidades profissionais que surgiram após a conclusão do curso de doutorado.

O estudo mostrou que, apesar das dificuldades de financiamento para cursar o programa, os egressos avaliam positiva a formação. Sentiram a necessidade de participar de mais eventos, mas cursar o programa, conhecer as três instituições polos, os docentes permanentes e colaboradores foi importante na formação doutoral.

A oportunidade de permanência na Amazônia Legal foi muito citada, pois, para muitos, não seria possível cursar doutorado em outros estados, por diversos motivos; muito deles não conseguiriam sair de sua localidade ou da região, e outros levariam mais tempo para realizar essa formação.

Ademais, a REAMEC se consolidou na formação de doutores na Amazônia Legal. Na última avaliação da Capes, quadriênio 2013-2016, o programa da Rede recebeu nota 5, tendo recebido o conceito 'Muito Bom' em todos os quesitos. No relatório da área de Ensino/Capes a comissão ressaltou que o programa atingiu índices para nota 6 , que só não ocorreu por decisão interna da comissão de avaliação. A Rede foi apontada, no relatório elaborado pela comissão de avaliação da Capes, como exemplo positivo para formar doutores e que pode servir de modelo para outras áreas do conhecimento.

\section{AGRADECIMENTOS}

À Fundação de Apoio e Pesquisa de Mato Grosso (FAPEMAT) e ao Instituto Federal de Educação, Ciência e Tecnologia de Mato Grosso (IFMT) pelo apoio financeiro.

\section{REFERÊNCIAS}

ALVES, A. C. T.; MELLO, I. C. Amazonian Education network in sciences and mathematics: Impacts in Phd formation for networking. Revista Prática Docente, v. 2, n. 2, 2017. Disponível em: http://periodicos.cfs.ifmt.edu.br/periodicos/index.php/rpd/article/view/107/43. Acesso em: 28 dez. 2019. 
ALVES, A. C. T.; MELlO, I. C. Rede Amazônica de Educação em Ciências: Consolidação na formação de doutores na Amazônia Legal. Latin American Journal of Science

Education. v. 6, 12014, 2019. Disponível em: http://www.lajse.org/may19/2019_12014.pdf. Acesso em: 28 dez. 2019.

BRASIL. A Criação de cursos por Associações de IES. CAPES. Brasília, DF, 2007. Disponível em:

http://www.capes.gov.br/images/stories/download/avaliacao/CriacaoCursos_Associ acaoIES2007.pdf. Acesso em: 01 out. 2019.

BRASIL. O que é? Amazônia Legal. Desafios do Desenvolvimento, IPEA, Ano 5, ed. 44, 2008. Disponível em:

http://www.ipea.gov.br/desafios/index.php?option=com_content\&id=2154:catid=28\&

Itemid=23. Acesso em 22 de maio de 2019.

BRASIL. Divisão Territorial Brasileira. IBGE. Brasília, DF, s.a. Disponível em:

http://www.memoria.ibge.gov.br. Acesso em: 03 mar. 2019.

BRASIL. Projeção da população do Brasil e das Unidades da Federação. IBGE. Disponível em:

https://www.ibge.gov.br/apps/populacao/projecao/index.html?utm_source=portal\&utm_medi

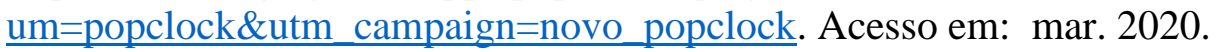

BRASIL. Proposta de curso novo na modalidade acadêmica em forma associativa. CAPES, Brasília, DF, 2014. Disponível em:

https://www.capes.gov.br/images/stories/download/avaliacao/avaliacao-n/852014Proposta-decurso-novo-na-forma-associativa.pdf. Acesso em: 03 out. 2019.

BRASIL. Ficha de Avaliação da REAMEC. Área de Ensino. Avaliação Quadrienal. CAPES, Brasília, DF, 2017.

BRASIL. Relatório de Avaliação: ENSINO. Avaliação Quadrienal. CAPES, Brasília, DF, 2017a. Disponível em: https://capes.gov.br/images/stories/download/avaliacao/relatoriosfinais-quadrienal2017/20122017-ENSINO-quadrienal.pdf. Acesso em: 24 mai. 2018.

CAVALCANTI, Alberes de Siqueira; MARTINES, Elizabeth Antonia Leonel de Moraes. A Formação Doutoral em Educação: repensando o estágio de docência para professores e professoras experientes. Revista REAMEC, Cuiabá - MT, v. 6, n. 1, 2018. Disponível em: http://periodicoscientificos.ufmt.br/ojs/index.php/reamec/article/view/5877/pdf . Acesso em 07 abr. 2020.

CUNHA, M. I. O tema da formação de professores: trajetórias e tendências do campo na pesquisa e na ação. Educação e Pesquisa. São Paulo, n. 3, p. 609-625, jul-set, 2013.

Disponível em: http://www.scielo.br/pdf/ep/v39n3/aop1096.pdf. Acesso em: 21 jun. 2018.

DARSIE, M. M. P. Programa de Pós-Graduação - Doutorado em Educação em Ciências e Matemática - PPGECEM - da Rede Amazônica de Educação em Ciências e Matemática - 
REAMEC. Revista Educação Pública. Cuiabá, v. 20, n. 43, p. 357-377, maio/ago. 2011. Disponível em:

http://periodicoscientificos.ufmt.br/ojs/index.php/educacaopublica/article/view/310. Acesso em: 03 out. 2019.

DAY, C. Desenvolvimento Profissional de Professores: os desafios da aprendizagem permanente. Porto, Porto Editora, 2001.

FREITAS, M. E. Viver a tese é preciso! In: BIANCHETTI, L, MACHADO, A. M. N. Orgs. A Bússola do Escrever: desafios e estratégias na orientação e escrita de teses e dissertações. 3 ed. São Paulo: Cortez, 2012.

HUBERMAN, M. O ciclo de vida profissional dos professores. In: NÓVOA, António (Org.). Vidas de professores. Porto: Porto, 2000, p. 31-62.

REAMEC. Projeto do Programa de Doutorado Educação em Ciências e Matemática. Cuiabá, 2008.

REAMEC. Edital 1. Cuiabá, 2010. Disponível em:

https://www.unir.br/noticias_arquivos/3114_edital_reamec_2011.pdf. Acesso em: 14 mai. 2019.

REAMEC. Processo Seletivo 2013/1 Doutorado em Educação em Ciências e Matemática/REAMEC. Cuiabá, 2012. Disponível em:

http://www.ufmt.br/ufmt/site/editais/detalhes/368/9/Cuiaba. Acesso em: 14 mai. 2019.

REAMEC. Processo Seletivo 2015/1 Doutorado em Educação em Ciências e

Matemática/REAMEC. Cuiabá, 2014. Disponível em:

http://www.ufmt.br/ufmt/site/editais/detalhes/657/9/Cuiaba. Acesso em: 14 mai. 2019.

REAMEC. Processo Seletivo 2017/1 Doutorado em Educação em Ciências e

Matemática/REAMEC. Cuiabá, 2016. Disponível em:

http://www.ufmt.br/ufmt/site/editais/detalhes/979/9/Cuiaba. Acesso em: 14 mai. 2019.

REAMEC. Processo Seletivo 2019/1 Doutorado em Educação em Ciências e

Matemática/REAMEC. Cuiabá, 2016. Disponível em:

https://www.ufmt.br/ufmt/site/editais/detalhes/1333/9/Cuiaba. Acesso em 01 ago. 2019.

Submetido em: 09 de março de 2020.

Aprovado em: 05 de abril de 2020. 